\title{
$\mathrm{P} H \mathbf{9 0}$

\section{Patrimonio megalítico del alto valle del Guadiato}

Juan Carlos Vera Rodríguez | Universidad de Huelva

M. ${ }^{a}$ José Martínez Fernández | Universidad de Huelva

URL de la contribución <www.iaph.es/revistaph/index.php/revistaph/article/view/3788>

\section{RESUMEN}

El alto valle del Guadiato esconde un monumental y rico patrimonio de construcciones megalíticas, la mayoría de ellas todavía por descubrir e investigar debidamente y, por supuesto, por conservar y proteger.

Este legado lo componen varias decenas de dólmenes de corredor, galerías cubiertas y sepulcros de falsa cúpula (tholoi), menhires y estelas-menhir, que fueron erigidos por las sociedades de los primeros agricultores y ganaderos y de los primeros metalúrgicos que habitaron el valle entre el quinto y el tercer milenio antes de nuestra era. Aunque algunos megalitos prácticamente han desaparecido, y otros se encuentran muy degradados, sus estructuras tumulares, ayer como hoy, caracterizan el paisaje comarcal, donde han permanecido a lo largo de milenios como hitos remarcables.

Fruto de muchos años de trabajos de campo e investigación que se remontan a más de un siglo, a lo largo de estas páginas repasamos brevemente la dispersión de los principales monumentos y necrópolis, destacando cuando ha sido posible sus arquitecturas, ya se conformen de grandes bloques (ortostatos), losas, mampostería o sus combinaciones, así como las ubicaciones relacionadas con los cursos de agua, lugares de paso ancestrales y los recursos económicos que se encuentran a lo largo y ancho del extenso valle que conforma este paisaje andaluz.

\section{Palabras clave}

Alto valle del Guadiato | Córdoba (provincia) | Dólmenes | Menhires | Necrópolis | Prehistoria reciente | Patrimonio megalítico | Tholos | Túmulos | 


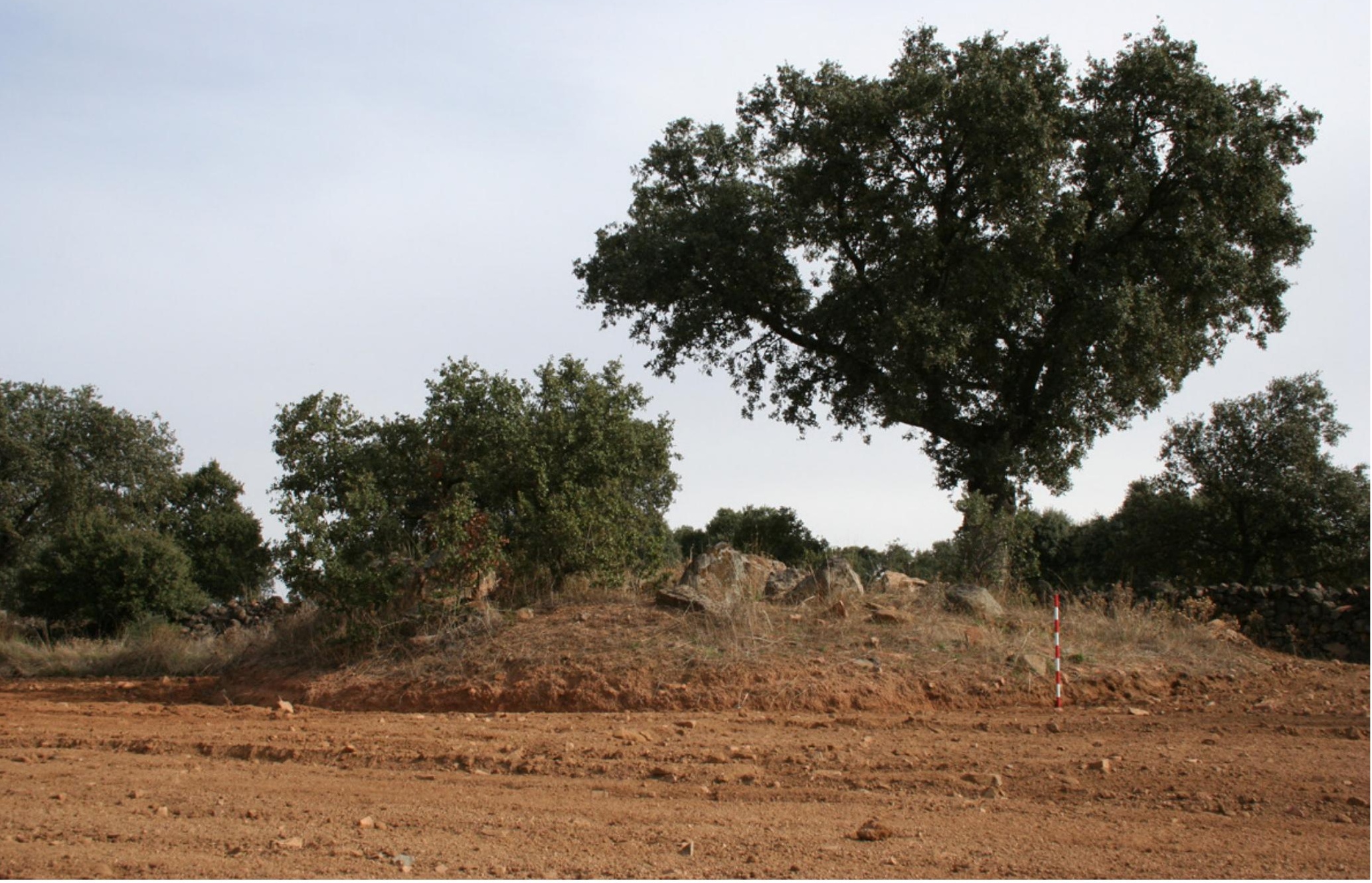

Dolmen de la Horma, de cámara poligonal y corredor | foto Juan Carlos Vera Rodríguez, autor de todas las imágenes que ilustran este texto si no se indica lo contrario 
La Base de Datos del Patrimonio Inmueble de Andalucía registra en la actualidad un total de cuarenta y dos entradas referentes a estructuras megalíticas y contextos funerarios de la prehistoria reciente, distribuidas entre los términos municipales de Fuente Obejuna, Belmez, Villanueva del Rey y Espiel. No obstante, siete de estas referencias son incompletas y se corresponden bien con errores de localización geográfica, bien con vagas alusiones toponímicas procedentes de publicaciones de inicios del siglo $\mathrm{XX}$, o se trata de meras duplicaciones de identificación a partir de citas bibliográficas. Por ejemplo, tres registros hacen referencia a otros tantos dólmenes extremeños muy próximos a los límites autonómicos, dándose incluso el caso de que uno de ellos aparece duplicado y atribuido simultáneamente a los términos municipales de Belmez y Fuente Obejuna.

Las treinta y cinco entradas restantes se encuentran debidamente actualizadas y redactadas conforme a los requisitos del Sistema de Información del Patrimonio Histórico de Andalucía (SIPHA), pero reflejan tan solo una parte del rico patrimonio megalítico del Alto Guadiato que, en función de las evidencias y la documentación actualmente disponibles, duplicaría la cifra de bienes catalogados en esta categoría.

Dolmen del Ovatón (según Siret, 1891) | fuente SIRET, 2001

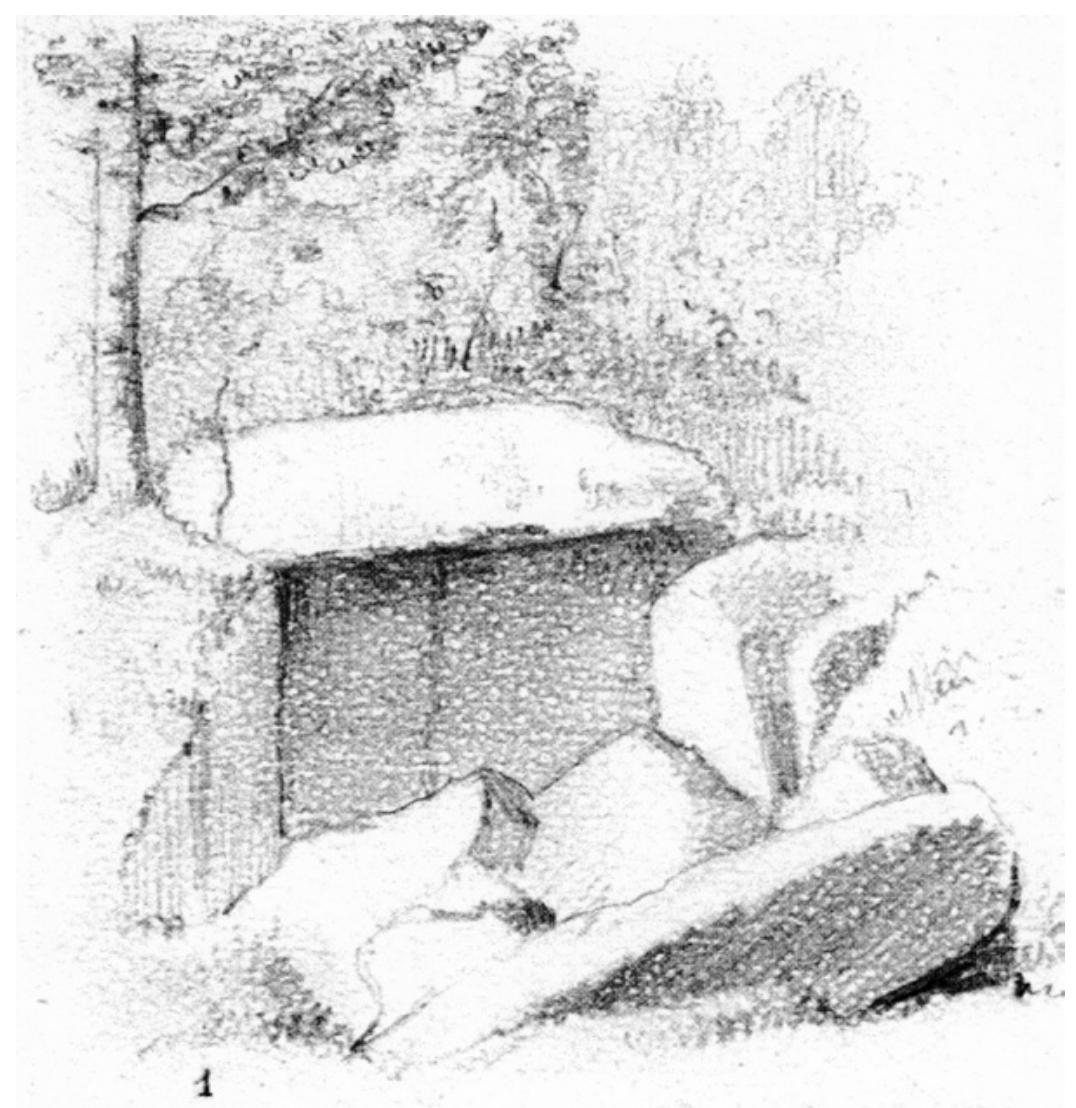


Las primeras exploraciones y referencias escritas relativas a la existencia de megalitos en la comarca se remontan a la última década del siglo XIX y son debidas a uno de los padres de la prehistoria andaluza, Luis Siret, quien hacia 1890 ya excavó dos de los dólmenes del Ovatón. A partir de los años 20 del pasado siglo, el también ingeniero de minas Antonio Carbonell fue divulgando en distintas publicaciones sus observaciones de campo alusivas a las evidencias megalíticas con las que se fue topando en este sector cordobés, precedentes que sirvieron para que tras la Guerra Civil el matrimonio de prehistoriadores alemanes G. y V. Leisner las visitasen y las incluyesen en su corpus sobre el megalitismo del sur peninsular publicado en 1943.

A partir de los años 50 se suceden una serie de expolios e intervenciones no regladas que incidieron muy negativamente en el conocimiento y la conservación de los monumentos, y no será hasta los años 80 y 90 cuando comiencen a ser integrados como objeto de estudio en tesis doctorales y trabajos de investigación universitarios. Coincidiendo con el traspaso de competencias, la Consejería de Cultura de la Junta de Andalucía se interesó por realizar los primeros inventarios y catálogos administrativos a partir de 1987 que, sin embargo, no han conseguido un adecuado nivel de protección para paliar el deterioro de este monumental pero frágil patrimonio. La investigación y la difusión son también una asignatura pendiente, pues hasta la fecha tan solo se han realizado tres intervenciones de urgencia en dos megalitos diferentes, dos de ellas de apoyo a la restauración, y tan solo existe un único monumento realmente puesto en valor, a pesar de algunas loables iniciativas que han promovido la Delegación Territorial de Cultura, los propios ayuntamientos o el GDR Alto Guadiato.

La mayor parte de los megalitos del Guadiato suelen estar agrupados en conjuntos de diferente extensión territorial y variable densidad de sepulcros, constituyendo auténticas necrópolis que en su mayor parte están situadas en las cercanías de la veintena de aldeas y poblados neolíticos y calcolíticos actualmente conocidos, en los que habitaron las sociedades que los construyeron y los utilizaron para materializar en ellos principalmente, aunque no de manera exclusiva, rituales funerarios y de culto a los antepasados. Diseminados en eje noroeste-suroeste a lo largo y ancho del valle principal y de sus tributarios, lugares de hábitat y megalitos suelen mantener conexiones espaciales y visuales mutuas.

Comenzando por la cabecera del río Guadiato, al suroeste de la localidad de Fuente Obejuna, encontramos el conjunto de los Delgados/la Sierrezuela, asociado a los poblados de Los Delgados y de La Calaveruela. A lo largo de una estrecha franja de terreno en sentido noreste-suroeste, entre las aldeas de La Coronada y Argallón, se distribuyen en un itinerario de escasos dos kilómetros un total de diez sepulcros megalíticos y algún menhir desplazado 
de su ubicación original. Las tipologías arquitectónicas de tales monumentos son variadas: dólmenes de cámara poligonal y corredor (La Horma) (imagen p.49), grandes galerías cubiertas (El Gigante), sepulcros de falsa cúpula que combinan alzados ortostáticos con fábricas de mampostería (Delgados 1, 2 y 3 y Sierrezuela 1), e incluso algunos túmulos aún intactos (Delgados 5 y 6 ), aunque otros se encuentran hoy en día parcialmente destruidos. Destaca el sepulcro denominado El Dorado (Delgados 1) por su complejidad arquitectónica y las dimensiones de su estructura tumular que supera los cuarenta metros de diámetro.

Otras necrópolis destacadas se localizan al norte de cañada del Gamo y Ojuelos Bajos, donde en un radio de un par de kilómetros se concentran hasta once megalitos divididos entre los grupos denominados los Pozos y Obatón. Se trata en este caso de arquitecturas ortostáticas adinteladas, correspondientes a galerías cubiertas y dólmenes de cámara poligonal y corredor, provistas de túmulos relativamente discretos que no superan los veinte metros. Constructivamente destaca Pozos 4, una pequeña galería que permite observar una interesante estructura intratumular consistente en una coraza de pequeños bloques trabados con arcilla que ocupan todo el espacio entre el paramento megalítico y un anillo peristalítico, es decir, de delimitación perimetral del túmulo, a base de bloques de mayor tamaño.

Además de estas grandes concentraciones, el resto de los megalitos mellarienses se localizan más dispersos, salpicando aquí y allá el paisaje de dehesas de las terrazas del Guadiato y de sus principales afluentes algunos monumentos cuyas grandes piedras afloran hoy en día, caso de las Corridas, junto a túmulos en apariencia intactos, como por ejemplo el Soto.

Ya en el término municipal de Belmez los megalitos más occidentales se ubican al noreste de Doña Rama, donde encontramos la agrupación de tres pequeñas galerías cubiertas separadas alrededor de unos trescientos metros. La mejor conservada, denominada Doña Rama 1, presenta una delineación de los paramentos que va convergiendo desde la cámara en dirección al exterior, lo cual es habitual en los sepulcros de esta tipología, pero presenta la particularidad de que su acceso forma una especie de estrangulamiento mediante la combinación de estrechas lajas de piedra con gruesos bloques ortostáticos que simétricamente sobresalen por el interior a manera de jambas, por lo que la "puerta" está precedida de un atrio.

Pero la mayor concentración de estructuras megalíticas se produce más al este, en la zona meridional de Belmez, entre la propia localidad y la pedanía de El Entredicho, donde se han descrito hasta ocho monumentos, en su mayor parte muy cercanos a los poblados prehistóricos de Sierra Palacios. 


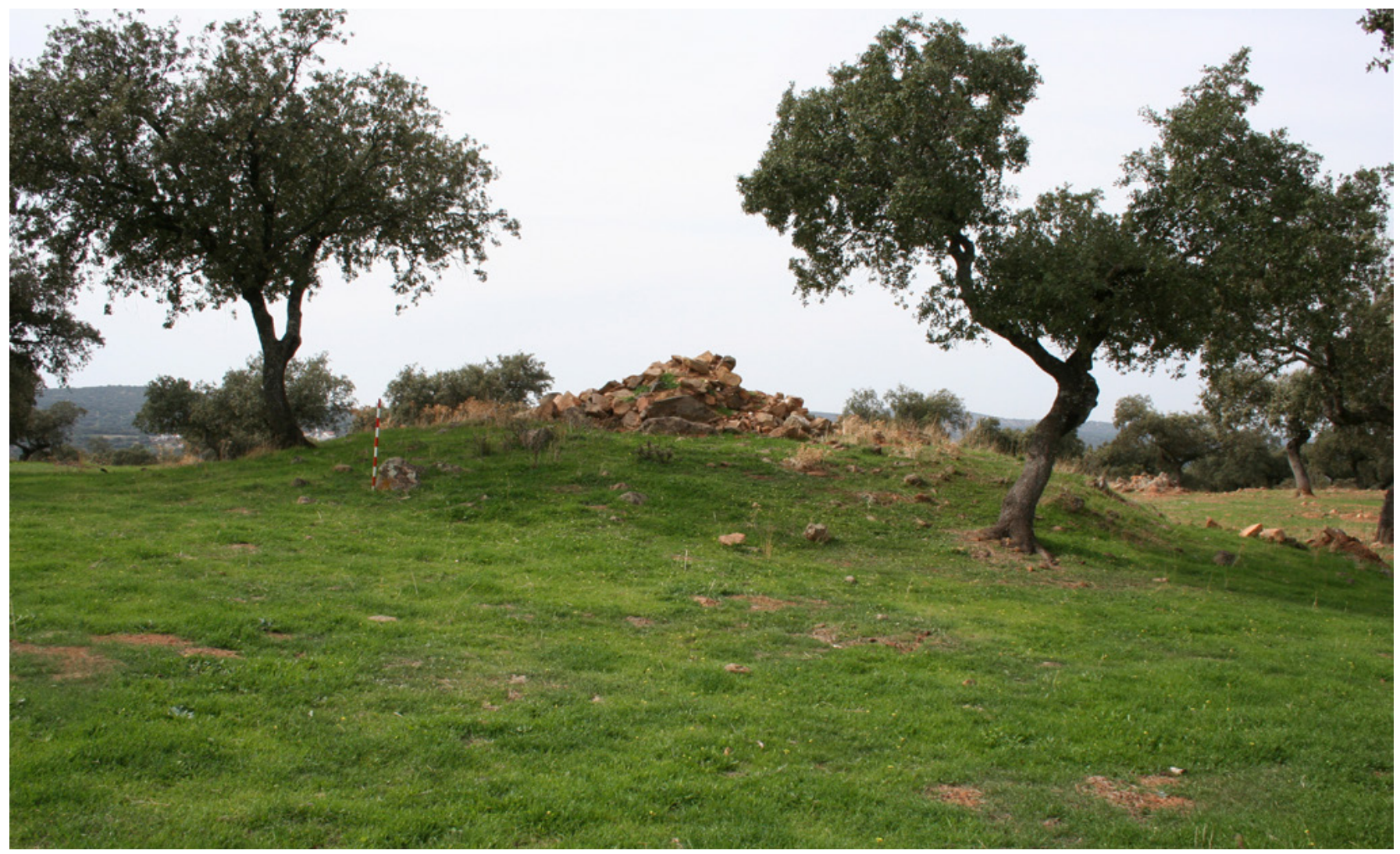

Túmulo de los Pozos 1
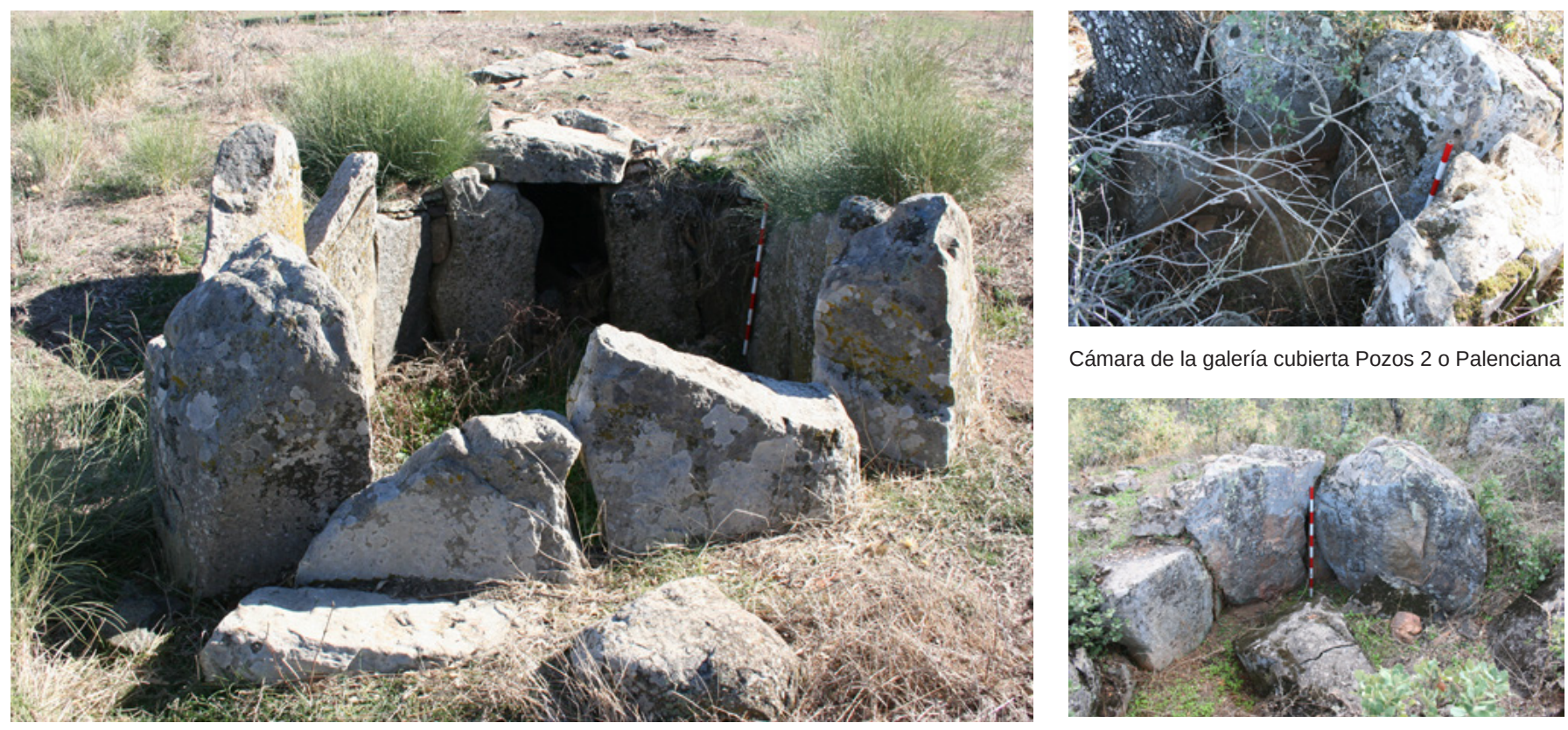

Cámara de la galería cubierta Pozos 2 o Palenciana

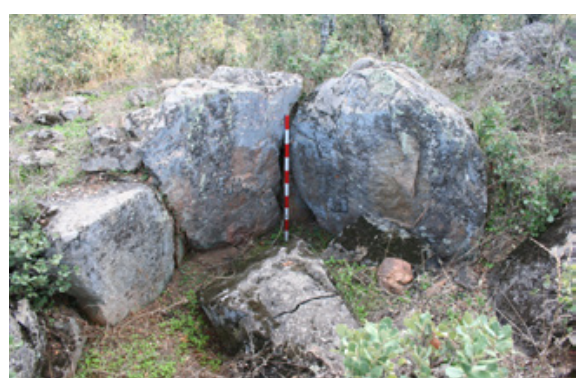

Cámara del tholos El Dorado

Cámara poligonal del dolmen Obatón 1 


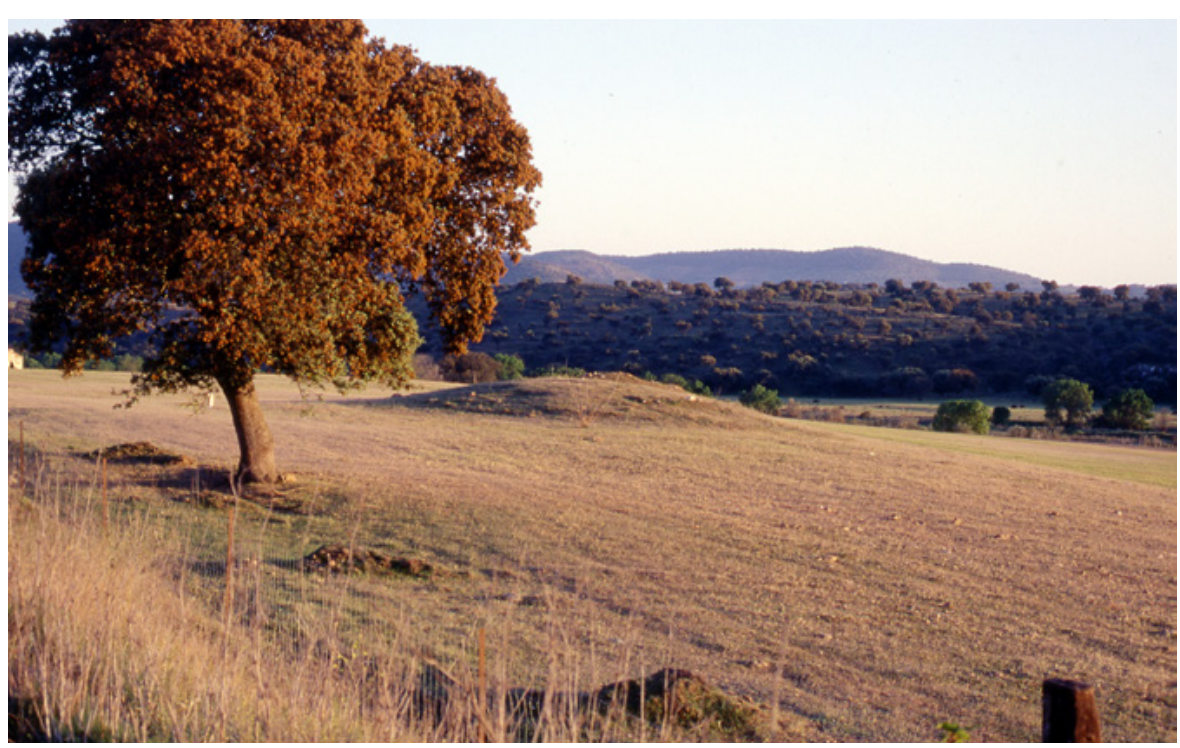

Túmulo de Cabeza de Vaca

Los contextos funerarios de la prehistoria reciente de este grupo se completan con un enterramiento colectivo en cueva natural -cueva Agustín- y otro presumiblemente individual en una grieta al amparo de un afloramiento rocoso en el paraje de La Retuerta, perteneciente ya a época campaniforme.

El más próximo a Sierra Palacios, en la margen izquierda del Guadiato, es Cabeza de Vaca, una estructura tumular que con unos dos metros de altura conservada domina la vega adyacente. Por desgracia, las labores agrícolas periódicas a las que se ve sometido van mermando paulatinamente el alzado y deformando el perímetro de un túmulo que aún así actualmente ronda los veinte metros. En la llanura que se abre hacia el oeste, sobre la margen derecha del arroyo Fresnedoso se alza el aún más impresionante túmulo de Vega del Fresno, con unas dimensiones de cincuenta metros de diámetro y alrededor de cuatro metros de altura. Presenta en su zona superior una gran zanja de intento de robo que parece no llegó a alcanzar la estructura dolménica.

Al otro lado del Fresnedoso, pero en la misma margen derecha del Guadiato, se localiza el dolmen de las Casas de Don Pedro, el megalito mejor conocido de la comarca, ya que en el se han realizado dos intervenciones arqueológicas en 1986 y 2001. Su estructura tumular tenía unas dimensiones similares a las del anterior, e incluso las superaba, pero desgraciadamente, desde que fue seccionada en 1986 con ocasión de la realización de desmontes del terreno de cara a poner la zona en regadío, distintas agresiones incluso posteriores a su declaración específica como Bien de Interés Cultural, han terminado por desfigurar la fisonomía de este importante yacimiento. 


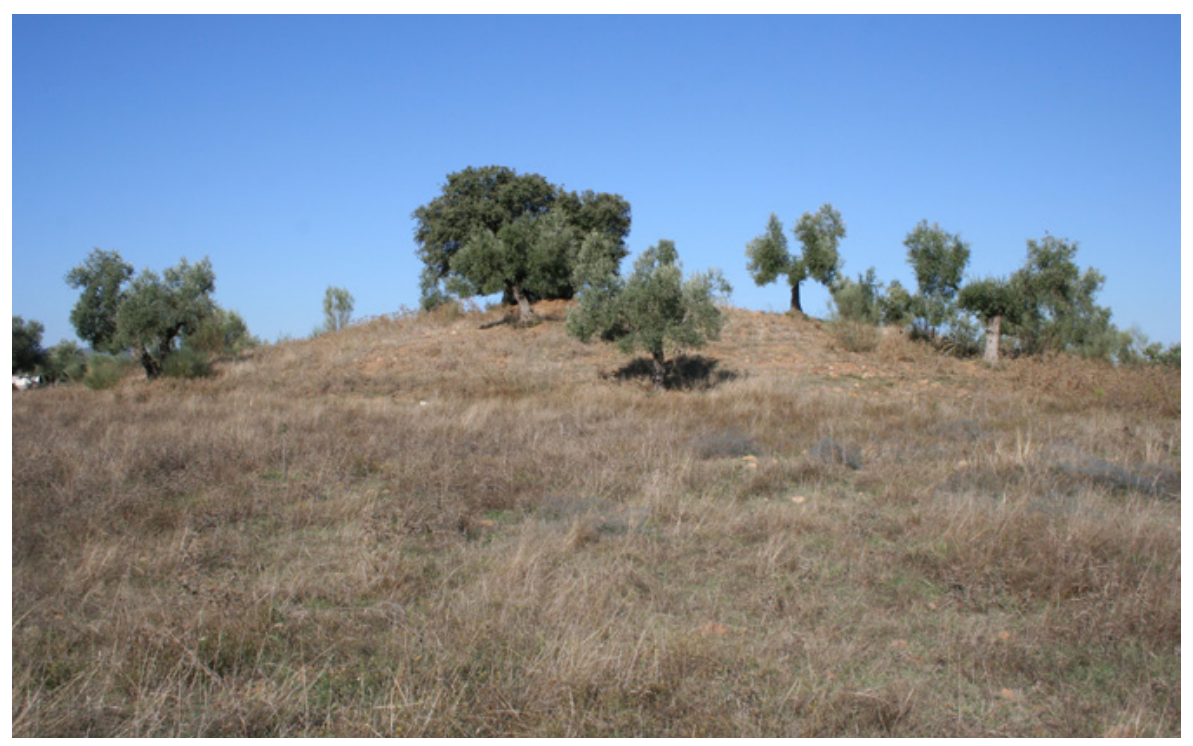

Se trata de un gran sepulcro ortostático que supera los tres metros de altura, con cubierta adintelada originalmente formada por al menos dos grandes losas, cámara de planta poligonal tendente al trapecio dividida en dos ámbitos mediante una pilastra central que ayuda al sostenimiento de la techumbre, y corredor corto. La altura de los ortostatos va aumentando progresivamente desde el acceso hasta el fondo interior del dolmen de las Casas y la longitud total de la estructura ronda los cinco metros por una anchura máxima de tres y medio.

La cámara está pavimentada con voluminosos cantos de río, bloques de dimensiones irregulares, alguna gran losa y arcillas apisonadas y para su confección se tuvieron en cuenta ciertos criterios estéticos. Así, la selección de los cantos de río estuvo condicionada por el cromatismo de su superficie, ya que todos presentan un color rojizo, mientras que otros bloques fueron coloreados de rojo carmín obtenido a partir de cinabrio. De otro lado, los restantes bloques eran de color oscuro o estaban oscurecidos intencionalmente por combustión, formando de esta manera una especie de alternancia cromática decorativa.

El acceso, ligeramente desviado hacia el norte con respecto al eje de simetría de la construcción, originalmente carecía de corredor. Las excavaciones han permitido detectar la existencia de varias etapas constructivas y de clausura del dolmen, relacionadas con dos fases generales de inhumación. En la primera el cerramiento consistía en un gran bloque de tendencia paralelepipédica combinado con un murete de piedra en seco, tras lo cual se añadió un auténtico corredor corto con cierre exterior que sufrió un posterior episodio de violación, para finalmente ser reparado y definitivamente clausurado.

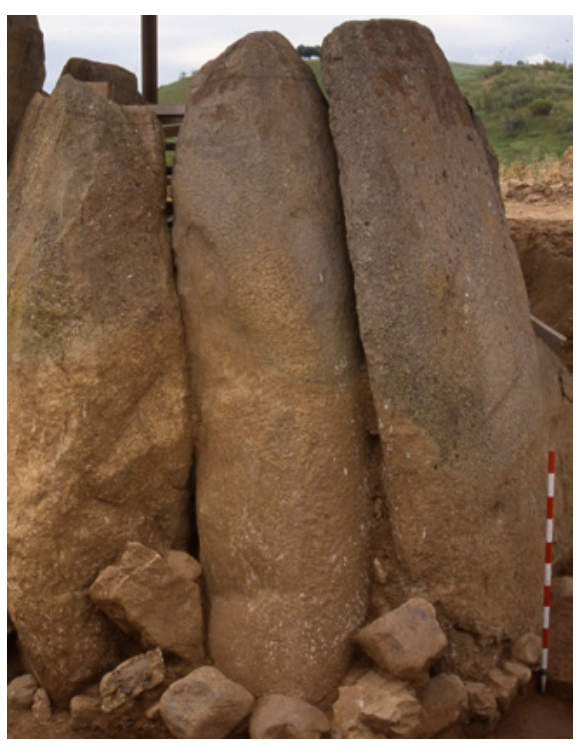

Túmulo de Vega del Fresno

Estelas-Menhir en la cabecera del dolmen de las Casas de Don Pedro 

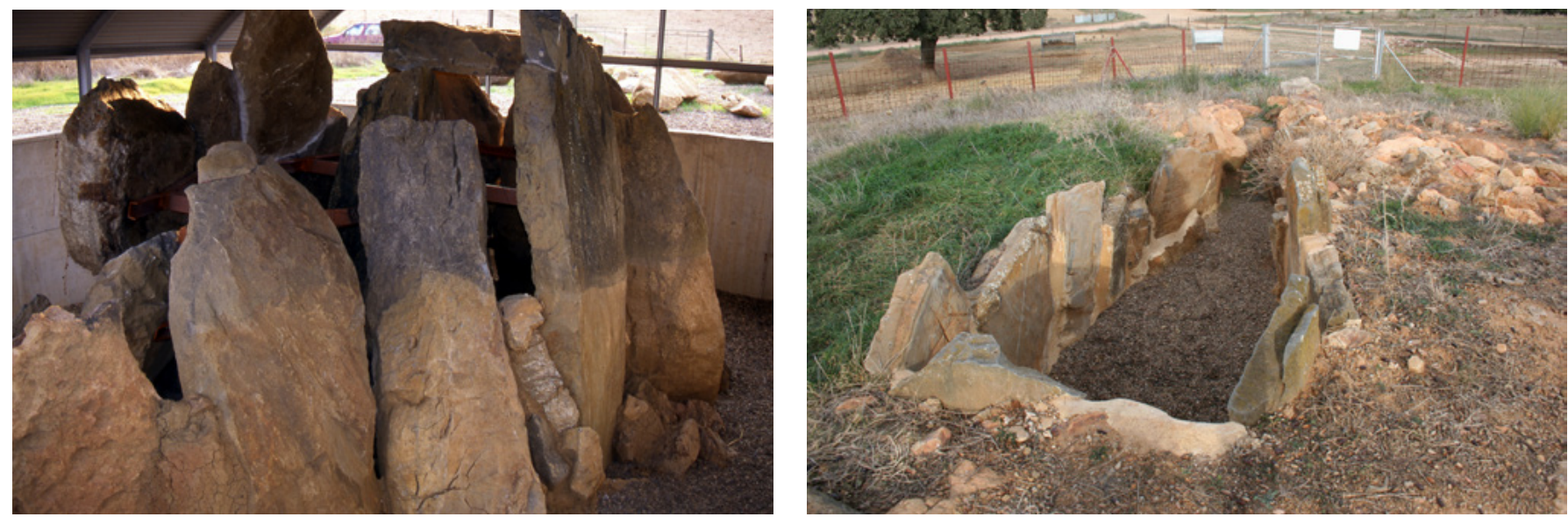

Paramento norte del dolmen de las Casas de Don Pedro

Las excavaciones en Casas de Don Pedro proporcionaron también una valiosísima información científica relativa a los orígenes del megalitismo andaluz, pues preservada bajo su estructura tumular se documentó una ocupación neolítica de la que se conservan tres hogares, una fosa, diversos agujeros de poste y suelos apisonados de color rojo por la mezcla de arcilla y óxidos de hierro, durante la que se erigieron al menos dos menhires o estelas-menhir, que posteriormente fueron aprovechadas en su misma ubicación para la construcción del dolmen.

Al sur de este importante yacimiento se localizan los túmulos gemelos denominados Agudelo 1 y 2, ya de dimensiones más discretas, separados tan solo unos setenta y cinco metros y, siguiendo siempre en dirección a El Entredicho, el sepulcro de la Fuente del Corcho, en las proximidades del manantial del mismo nombre, una de cuyas losas aparece decorada con motivos de "cazoletas" mediante la técnica de piqueteado.

Algo desplazado hacia el suroeste, más próximo al grupo de Doña Rama, se encuentra el sepulcro del Cortijo Viejo, el único e interesantísimo ejemplar de tholos belmezano a juzgar por las evidencias arquitectónicas que afloran en superficie. Un pequeño túmulo de poco más de doce metros y delimitado por un anillo construido a base de bloques irregulares dispuestos contiguamente, contiene una cámara de planta ovoide con cubierta de falsa cúpula derrumbada y corredor largo que sumarían unos seis metros de longitud total.

La concentración de monumentos continúa hacia la zona oriental del valle del Guadiato con otros grandes túmulos como el de los Prados, localizado ya en el término municipal de Villanueva del Rey. Esta estructura tumular se acerca casi a los treinta metros de diámetro y llega a alcanzar una altura aproximada de dos metros sobre el terreno circundante. En la zona superior 

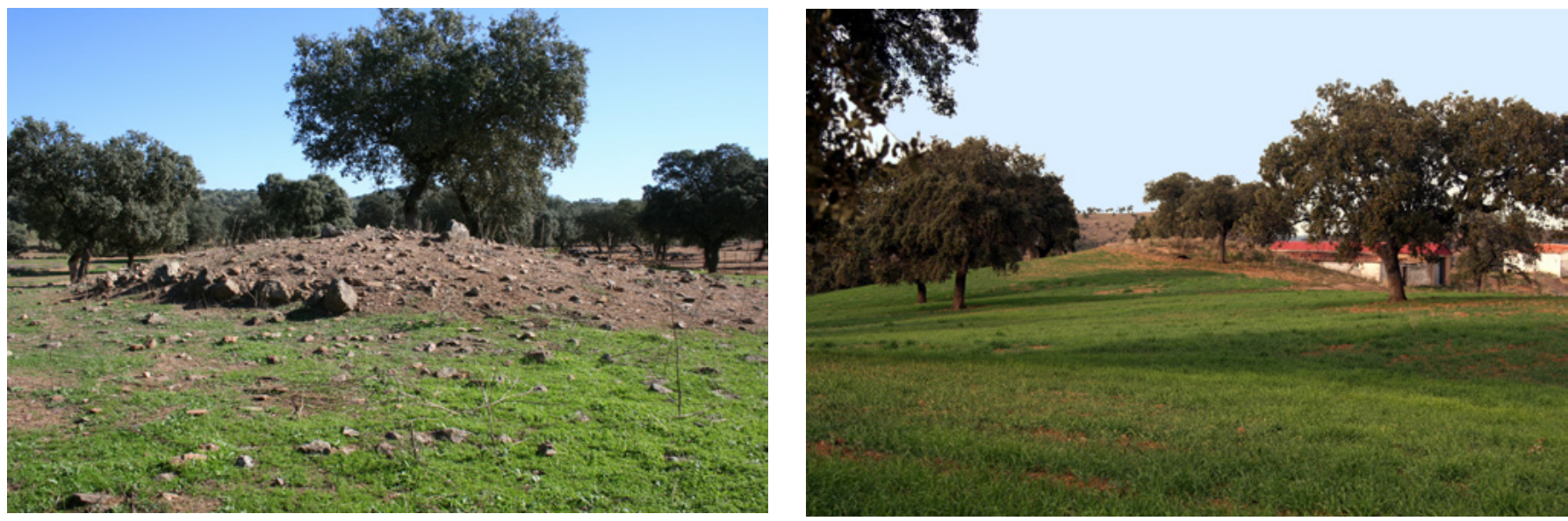

Tholos del Cortijo Viejo Túmulo de los Prados

del túmulo existe un gran bloque en posición vertical que muy posiblemente podría tratarse de un menhir.

Si bien existen referencias respecto a la existencia de otros megalitos en Villanueva del Rey, como los identificados con los topónimos Mina de Don Juan y Puerto Cacho, tan solo se ha catalogado hasta la fecha en su término otro monumento denominado San Antonio o la Jabalina. Se trata de una estructura tumular cercana a los doce metros y delimitada por un anillo perimetral de bloques que resultó parcialmente destruida hace una veintena de años al procederse a la apertura de una nueva pista en los terrenos de la explotación minera. El interés del monumento y su entorno inmediato se acrecienta por la presencia de un ortostato decorado con "cazoletas", que originalmente formaba parte de la estructura, así como de otro con similar decoración desplazado unos metros más al sur.

Continuando aguas abajo por el término municipal de Espiel, antes de que el río comience a encajonarse en zonas más abruptas de Sierra Morena, llegaremos a la sierra del Castillo, donde la acción de una cantera descubrió hace un siglo un enterramiento prehistórico en cueva natural del que se conserva un ídolo placa decorado. Debido a la escasez de trabajos de campo realizados, los megalitos catalogados de Espiel se reducen tan solo a tres túmulos aislados.

El más próximo a la localidad es el túmulo de Huerta del Caño 1, una gran estructura tumular de cuarenta metros de diámetro y casi tres metros de altura que se alza en la antigua margen derecha del Guadiato, frente a las estribaciones más occidentales de la sierra del Castillo donde se localiza el poblado prehistórico. Puesto que se ubica aguas arriba de la presa de Puente Nuevo, el túmulo se halla estacionalmente sumergido parcial o totalmente bajo el nivel de aguas. 

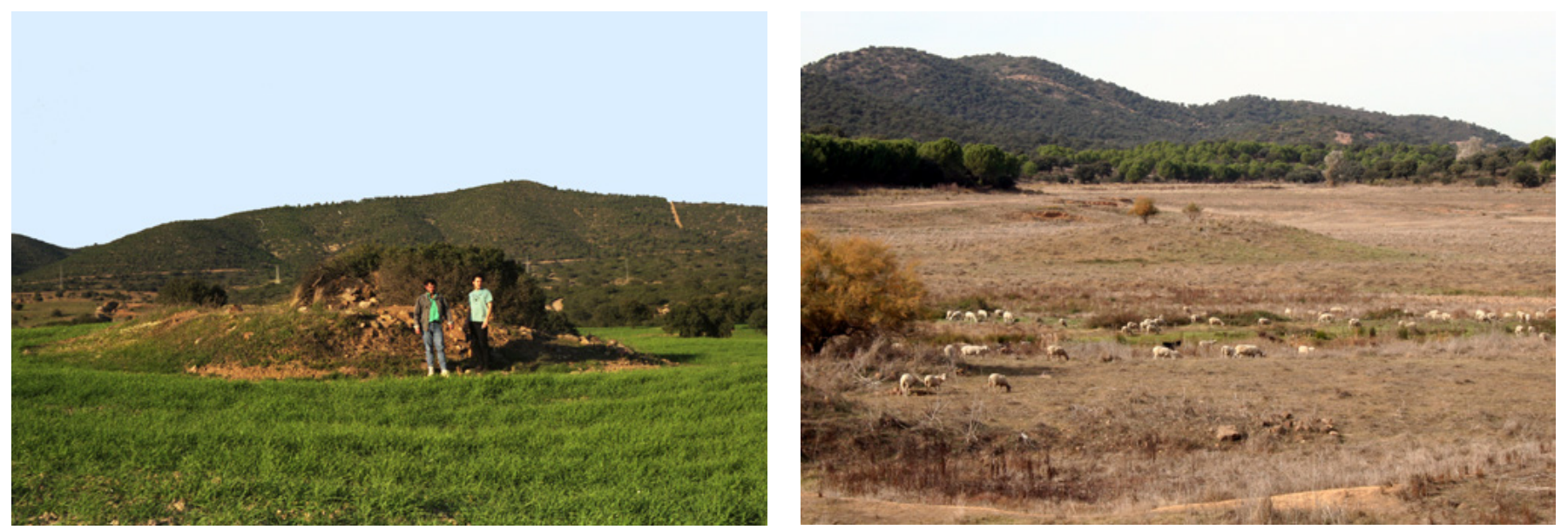

Retrospectiva del túmulo de San Antonio en 1988

Túmulo de Huerta del Caño 1 en la ribera del Guadiato

Las otras dos estructuras catalogadas se localizan más al norte, caso del túmulo del Valle, o al suroeste del primero, como el túmulo del Vínculo y son de dimensiones más discretas. Puesto que en todos se conservan las masas tumulares, nada puede decirse por el momento respecto a las arquitecturas megalíticas que contienen.

En conclusión, los megalitos del alto valle del Guadiato constituyen un exponente singular tanto de su (pre)historia como de su paisaje cultural. Como hemos visto están imbricados en antiguas rutas de paso y caminería, pues en muchas ocasiones aparecen pareados, muy próximos, en una y otra orilla de los más importantes cursos fluviales del valle, como ejemplifican los tholoi de los Delgados 1 y 2 (Fuente Obejuna), que jalonan las márgenes del propio río Guadiato a unos 2,5 km de su nacimiento, o el dolmen de Casas de Don Pedro y el túmulo de Vega del Fresno (Belmez) que enseñorean el paso del principal vado del arroyo Fresnedoso con sus imponentes arquitecturas tumulares. Junto a las riberas demarcan también las entradas y salidas de importantes vados del río Guadiato el túmulo de El Soto (Fuente Obejuna), el de Cabeza de Vaca (Belmez) o el de Huerta del Caño (Espiel). La ubicación de los megalitos, ya sean sepulcros o menhires, también se relaciona estrechamente con los principales recursos económicos comarcales de ayer y de hoy, agricultura, ganadería y minería, ya que habitualmente deslindan los suelos de vega, agronómicamente más fértiles, los territorios de mejores pastos, o contornean las zonas de mayor abundancia de antiguos filones de cobre y otras materias primas beneficiables. 


\section{BIBLIOGRAFÍA}

- CABRERo GARCíA, R. (1988) El yacimiento calcolítico de Los Delgados. Fuente Obejuna (Córdoba). Córdoba: Publicaciones del Monte de Piedad y Caja de Ahorros de Córdoba, 1988

- CARBONELL Y TRILLO-FIGUEROA, A. (1925) Valores prehistóricos de la Cuenca Alta del Guadiato. B.R.A.Co. 13, 1925, pp. 291-300

- CePILlo GALVín, J. J. (1997) El poblamiento y el mundo funerario durante el Calcolítico en el Alto Valle del Guadiato: el asentamiento humano de la Calaveruela y su necrópolis megalítica (Fuente Obejuna, Córdoba). En BUENO RAMÍREZ, P.; BALBÍN BEHRMANN, R. DE (coords.) II Congreso de Arqueología Peninsular: Zamora, del 24 al 27 de septiembre de 1996, vol. 2. sl: Fundación Rei Alfonso Henriques, 1997, pp. 263-272

- GAVILÁN, B.; VERA, J. C. (1994) Aproximación al Fenómeno Megalítico en el Alto Valle del Guadiato, (Córdoba). En Actas del II Congreso de Historia de Andalucía (Córdoba, 1991), vol. 1. Sevilla: Consejería de Cultura y Medio Ambiente; Córdoba: Obra Social y Cultural Cajasur, 1994, pp. 133-146

- GAVILÁN, B.; VERA, J. C. (2004) Excavación arqueológica (I.A.U. de apoyo a la restauración) en el Dolmen de las Casas de Don Pedro (Belmez, Córdoba). En Anuario Arqueológico de Andalucía, 2001, Vol. 3, Tomo 1: Actividades de urgencia. Sevilla: Consejería de Cultua, Junta de Andalucía, 2004, pp. 291-296

- GAVILÁN, B.; VERA, J. C. (2005) Neolítico y Megalitismo prefunerario en Andalucía. En Actas del III Congreso del Neolítico en la Península Ibérica (Santander, 5-8 de octubre de 2003). Santander: Universidad de Cantabria, 2005, pp. 535-541 (Monografías del Instituto Internacional de Investigaciones Prehistóricas de Cantabria 1)

- MARTín DE LA CRUZ, J. C.; VERA, J. C. (2002) Historiografía del megalitismo en la provincia de Córdoba. En Actas del II Congreso de Historia de Andalucía (Córdoba, 2001), vol. 1. Sevilla: Consejería de Cultura y Medio Ambiente; Córdoba: Obra Social y Cultural Cajasur, 2002, pp. 121-173

- MARTínEZ, R. M.; LIÉBANA, J. L. (2002) El Valle del Guadiato y sector noroccidental. En Actas del II Congreso de Historia de Andalucía (Córdoba, 2001), vol. 1. Sevilla: Consejería de Cultura y Medio Ambiente; Córdoba: Obra Social y Cultural Cajasur, 2002, pp. 130-142

- VERA ROdRíguez, J. C. (1999) El Calcolítico en el Alto Valle del Guadiato: los hábitats y las necrópolis prehistóricas del entorno de Sierra Palacios. Córdoba: Servicio de Publicaciones, Universidad de Córdoba, 1999
- VERA ROdRíguez, J. C. (2004) Formación y desarrollo de las primeras sociedades metalúrgicas en la comarca minera del Alto Valle del Guadiato. En III Simposio de Prehistoria Cueva de Nerja: Las primeras sociedades metalúrgicas en Andalucía. Homenaje al Profesor Antonio Arribas Palau (Nerja, 2000). Nerja: Patronato de la Cueva de Nerja, 2004, pp. 321-329

- VERA RODRíGUEZ, J. C. (2004) El megalitismo en la prehistoria reciente de Andalucía. Andalucía en la Historia, 7, 2004, pp. 76-83

- SIRET, L. (2001) España Prehistórica. Traducción del manuscrito L'Espagne préhistorique (1891). Almería: Consejería de Cultura, Junta de Andalucía, 2001 